\title{
REPRESENTACIONES SOCIALES DE LA ESCUELA EN JÓVENES URBANO POPULARES DESESCOLARIZADOS
} Ex-cuela y juventud popular: la escuela desde la desescolarización

\author{
RODOLFO SAPIAINS ARRUÉ* \\ PABLO ZULETA PASTOR ${ }^{* *}$
}

\section{INTRODUCCIÓN}

A LO LARGO DE la tradición histórica de nuestro país, se le ha otorgado a la educación un papel fundamental en materias de superación de la pobreza, así es como durante el presente siglo se han sucedido diversas iniciativas educacionales desde el Estado; «El Estado Docente» de 1925, la bien conocida consigna de que «gobernar es educar» de 1939, la «planificación educativa para el desarrollo» de 1964, «la educación liberadora» de 1967, hasta la actual «reforma educativa en marcha», eje central de los dos últimos gobiernos de la concertación (Salazar, 1996:31).

El dicho popular de «mientras más va el cántaro al agua...» no cobra manifestación real en el área de la educación; la manoseada frasecita «con más educación, los pobres podrán superar su condición de pobreza», no deja de ser un clisé burlesco para los educandos de los sectores más desfavorecidos de nuestro país. Basta consignar las actuales cifras de pobreza y desigualdad, según las cuales en nuestro

* Psicólogo, Universidad de Chile. E-mail: rsapiains@yahoo.com.

** Psicólogo, Universidad de Chile. 
país existen más de tres millones de pobres y una creciente inequidad en la distribución de los ingresos, donde el 10\% más pobre se lleva el $1,5 \%$ de los ingresos monetarios y el $10 \%$ más rico el $41 \%$ (MIDEPLAN, 1999). Todo lo anterior no obstante la considerable y exitosa ampliación de la cobertura educacional de nuestro país.

Ante tal situación cabe preguntarse el por qué: ¿es que no es la educación el camino correcto para intentar modificaciones en la estructura social de nuestro país; o es que todos estos intentos reformistas, particularmente la reforma en vigencia, llevan en sí la idea del transformismo del que habla Moulian; ${ }^{1}$ es decir, cambiar para permanecer? Pues una cosa es clara: «la macro-pobreza permanece, pese a la macro-educación» (Salazar, 1996:32).

Expuesto este contexto general, nos situamos ahora en la particularidad de nuestra investigación, en la que intentamos aproximarnos a la compleja relación existente entre educación y pobreza, y más específicamente entre jóvenes urbano populares y la escuela, desde la perspectiva de la desescolarización.

El texto que aquí se presenta, se estructura en cuatro partes; una primera en la que se definen los conceptos básicos y se reseña brevemente la metodología utilizada; una segunda, en la que se realiza un análisis en base a los resultados obtenidos, una tercera en que se desarrolla una síntesis y discusión, para finalizar con una cuarta en la que se exponen algunas reflexiones y propuestas.

\section{CONCEPTOS Y METODOLOGÍA}

\section{Conceptos básicos}

\section{a) Las representaciones sociales}

Optamos por las representaciones sociales, pues pensamos que ellas permiten aproximarnos al conocimiento que del objeto social escuela tiene el sujeto social joven urbano popular desescolarizado, desde su experiencia individual y colectiva.

1 Moulian llama transformismo a las operaciones que en el «Chile Actual» se realizan para asegurar la reproducción de la infraestructura creada durante la dictadura, despojada de las molestas formas, de las brutales y de las desnudas superestructuras de entonces... consiste en una alucinante operación de perpetuación que se realizó a través del cambio del Estado, pero manteniendo inalterado el aspecto sustancial: el modelo económico neoliberal. 
Se trata de un constructo más amplio que el de actitudes, valores, opiniones, creencias, y que de alguna manera, los abarca. La representación social resulta ser ante todo un producto sociocultural que a la vez es pensamiento constituido (entendido como producto que interviene en la vida social como estructura preformada que sirve como marco de interpretación), y un pensamiento constituyente (interviene en la construcción de la realidad).

Diremos dos cosas que pueden llegar a parecer obvias, pero que es indispensable explicitar. La primera es que una representación social estará definida por un contenido (sean imágenes, informaciones, actitudes u otro) con respecto a un objeto (sean situaciones, acontecimientos, personas, instituciones, etc.). La segunda es que la representación social siempre es de un sujeto (entiéndase individuo, grupo social o familiar, equipo, etc.), en relación a otro sujeto. «De esta forma, la representación social es tributaria de la posición que ocupan los sujetos en la sociedad, la economía, la cultura» (Jodelet, 1986:475).

En definitiva, entenderemos las representaciones sociales como las imágenes y los modelos explicativos que un determinado grupo social posee de algún fenómeno o contenido de su realidad (Farr, 1984) y que se constituye como una herramienta conceptual que posibilita establecer un nexo entre el individuo, la cultura y la historia, es decir, entre la subjetividad y la vida social de los seres humanos (Krause, 1996:13).

\section{b) La escuela: el objeto a representar}

Entenderemos la escuela como una institución en la que se depositan la responsabilidad y la confianza para que las nuevas generaciones de la especie humana adquieran o desarrollen conocimientos y habilidades necesarios para desenvolverse en la sociedad. La escuela enseña a nuestros niños y jóvenes todo lo que es importante que sepan y no pueden adquirir en el seno de su familia, agregando como componente fundamental la evaluación.

Es una institución social especialmente creada como administradora de conocimientos y habilidades, con un espacio físico concreto, con una distribución del tiempo particular en su interior, y una serie de normas. Es el lugar de paso obligatorio para constituirse en un adulto responsable y donde, además, se aprenden las pautas de comportamiento socialmente aceptadas. En tanto institución, nosotros abordaremos a la escuela como un componente del todo social que 
tiene una función de conservación y reproducción del equilibrio del sistema (Fernández Enguita, 1990).

En relación al proceso de escolarización propio de la institución escolar, consideraremos cuatro ideas fundamentales para comprender y desarrollar el concepto: i) Las escuelas no pueden ser analizadas como instituciones separadas del contexto socioeconómico en el que están situadas. ii) Las escuelas son sitios políticos involucrados en la construcción y control de discurso, significado y subjetividades. iii) Los valores del sentido común y las creencias que guían y estructuran las prácticas en la sala de clases, no son universales a priori, sino que son construcciones sociales basadas en supuestos normativos y políticos específicos. iv) La socialización dada en la escuela no es un simple vehículo de transmisión del orden social, sino que agencia de control social que funciona para ofrecer formas diferenciadas de enseñanza a diferentes clases sociales (Apple, citado por Soto, 1995).

c) Jóvenes urbano populares desescolarizados: el sujeto de la representación

Comprendemos la juventud, en toda su amplitud y diversidad, como aquel segmento de la estructura social, que, en relación al poder, ocupa un lugar desfavorable, la toma de decisiones respecto al mundo social no le compete a la juventud.

En este marco distinguimos un primer nivel de exclusión, que podríamos llamar propia de la condición juvenil respecto del mundo adulto. En el caso de la juventud urbano popular nos encontramos con un nuevo nivel de exclusión: la pobreza. En esta medida, la exclusión es doble; se es joven y pobre al mismo tiempo. Podemos mencionar un tercer nivel de exclusión: el nacer y vivir en un país del tercer mundo. Esto implica una limitación considerable de las garantías sociales que el Estado ofrece por el solo hecho de existir.

Dávila caracteriza a la juventud urbano popular como aquella que «deambula entre la resolución de necesidades concretas y prácticas, e intenta respuestas en vista de la configuración de un proyecto de vida que les permita acceder a los bienes y beneficios que la sociedad ofrece para algunos, en un símil de carrera que se necesita correr y donde muchas veces los resultados ya se saben, o se tiene perdida antes de correr» (Dávila, 1998:82).

Se trata, por cierto, de jóvenes que habitan en sectores populares urbanos, los que se identifican como aquellos que viven en situa- 
ción de pobreza o de privación respecto a los bienes y servicios (Weinstein, 1990).

Elemento central a la hora de definir a esta juventud, lo constituye la posición social de las familias a las que pertenecen, pues dada la precariedad de la situación económica, muchos de estos jóvenes se ven obligados a desertar de la escuela para buscar algún empleo y contribuir así a la economía del hogar. Mas, dada la dificultad de encontrar trabajos estables, estos jóvenes se incorporan masivamente al sector informal de la economía, o a trabajos temporales y/o subempleados.

Un millón y medio de jóvenes chilenos de quince a veinticuatro años no tiene educación media completa, ${ }^{2}$ es decir, alrededor de la mitad de los jóvenes chilenos que se encuentran en este rango etáreo.

La relevancia del tema, en consecuencia, es evidente. El sistema educacional chileno ha procurado otorgar a todos los chilenos la igualdad en las oportunidades de ingreso a la enseñanza básica (aumento de la cobertura educacional), no obstante, no da garantías de una igualdad de oportunidades de resultado (calidad de la educación).

\section{Metodología}

Para aproximarnos a las representaciones sociales, fue menester utilizar metodologías cualitativas, dentro de las cuales optamos por la entrevista abierta semiestructurada. Se trabajó con 13 jóvenes urbano populares desescolarizados, de la Villa Primavera, en el sector El Castillo de la comuna de La Pintana. Todos jóvenes entre los 15 y los 19 años que en el mejor de los casos habían aprobado el octavo año básico. La muestra estuvo compuesta por siete hombres y seis mujeres.

\section{ANÁLISIS DE LOS RESULTADOS}

\section{Construcción de núcleos figurativos}

En función de la descripción de los resultados en base a las dimensiones de las representaciones sociales (información, actitud y campo representacional), construimos dos núcleos figurativos, los que a nuestro juicio, aglutinan y ordenan los conocimientos e imágenes

2 Carmen Bravo, La Nación, Santiago, lunes 23 de agosto de 1999. 
producidos a partir del discurso de los jóvenes entrevistados de acuerdo a cuatro ejes: lo vincular, lo instruccional, lo disciplinario y lo instrumental.

i) La escuela como el escenario social en el que la dinámica juvenil se desarrolla de manera tutelada y orientada por la institución, $\mathrm{y}$ a la cual se le reconoce la pertinencia total en materias formativas, justificándose sus normas y códigos disciplinarios y validándose los métodos y las relaciones sociales que a estos fines se ajusten. La escuela se constituye como el espacio social exclusivo para que los niños y jóvenes se desarrollen y aprendan lo necesario para ser personas útiles a la sociedad y puedan aspirar a mejores condiciones de vida.

ii) La escuela como el escenario social en el que la dinámica juvenil se desarrolla de manera normada y vigilada por la institución, la que decide e impone el qué y el cómo se instruye, además de establecer un régimen disciplinario represivo y coercitivo al que los jóvenes tienen que someterse o ser castigados; lo que se sustenta y se representa en las relaciones autoritarias y jerarquizadas con los adultos significativos de la institución. La escuela se constituye como un espacio social ajeno e impuesto a los jóvenes y junto con esto representa escasas o nulas posibilidades, tanto para el desarrollo personal, como para el mejoramiento de las condiciones de vida.

\section{Análisis en base a los núcleos figurativos construidos}

\section{a) Primer núcleo: la escuela como un derecho;} necesaria e imprescindible

La construcción del primer núcleo figurativo surge desde el discurso de un grupo de los jóvenes entrevistados; aquellos que vivencian su condición de desescolarizados asociada a sentimientos de pérdida en todos y cada uno de los ejes en torno a los cuales se articula esta representación social de la escuela.

En el discurso de este grupo de jóvenes, la escuela aparece como un espacio social validado; tanto en sus formas, como en sus funciones, y al mismo tiempo como un espacio social validador de los jóvenes como individuos, en tanto desempeñan el rol de estudiante.

En esta medida, las relaciones sociales que se establecen en la escuela, además de tener un fuerte componente afectivo, son vividas como legítimas en tanto se dan en el seno de la institución. Así, no es lo mismo un compañero de curso que un vecino desescolarizado, ni 
jugar un videojuego en la sala de computación de la escuela, que en los flippers de la esquina de la casa, aunque las actividades y motivaciones en ambos casos sean las mismas. La escuela aparece como el único lugar posible para obtener una identidad juvenil positiva y reconocida, igualándose, en la experiencia de este grupo de jóvenes, la condición juvenil con la condición de estudiante.

Del mismo modo, las relaciones sociales establecidas entre este grupo de jóvenes y los adultos significativos en el espacio escolar, está mediada por la atribución dada a la escuela como la única institución dueña de los saberes y de los poderes necesarios para desempañar el rol educador en la sociedad. En este contexto, son los adultos significativos del medio escolar los que encarnan estas atribuciones; lo que se traduce en la legitimación y consecuente aceptación de estilos de relaciones interpersonales, que en nuestras escuelas se encuentran preferentemente marcadas por la jerarquía y el autoritarismo, constituyéndose estos componentes, muchas veces, como imprescindibles y demandados por alumnos y apoderados (los que exigen una disciplina más severa) como garante de la buena formación de los niños y jóvenes.

La formación disciplinaria represiva y coercitiva, aun cuando sea vivida como positiva y necesaria, tiene un claro límite en el discurso de los jóvenes: la agresión física como castigo. A pesar de todas las atribuciones otorgadas a la escuela para formar y educar a sus estudiantes, el uso de la violencia física es fuertemente rechazado, y por ende, excluido de la potestad otorgada a la institución.

Estas relaciones interpersonales entre jóvenes y adultos significativos tienen su manifestación más importante en el plano instruccional, el que además es el temporalmente más significativo; en éste, la relación se ve reducida a la entrega de conocimientos y a la mantención de un clima que lo permita, siendo la profesora o el profesor el ser omnisapiente que ha de procurar el traspaso de conocimientos desde una posición de saber hasta la posición de los ignorantes.

La escuela, en esta representación social, continúa siendo la institución garante de las aspiraciones futuras; continúa siendo el camino único y apropiado para el acceso a mejores condiciones de vida, y el único espacio social capaz de formar personas que se integren y sean útiles a la sociedad. 


\section{b) Segundo núcleo: la escuela como obligación;} controladora y descontextualizada

La construcción del segundo núcleo figurativo surge a partir del discurso de un grupo de jóvenes que manifiesta sentimientos de incomodidad, desagrado y malestar asociados a la temática escolar en general, y a la institución escuela en particular. Esta representación social da relevancia, en términos positivos, de manera exclusiva al plano vincular y afectivo con el grupo de pares; entendiendo por esto la dinámica juvenil que en el escenario escolar se desarrolla y en cierto modo, a pesar de las normas y la vigilancia, la escuela posibilita.

Mas, lo realmente significativo resultan ser los sentimientos negativos asociados a los ámbitos disciplinario, instruccional, vincular con los adultos e instrumental. Se trata de un malestar más emotivo que reflexivo, que sitúa a la escuela como un espacio que les resulta ajeno, impropio, impuesto y al que no logran adaptarse.

Se trata de una institución en la que las relaciones sociales, particularmente con los adultos significativos, son fundadas en la obediencia y el respeto a la autoridad; respeto muchas veces incomprendido y otras tantas intolerado; pues se trata de una disciplina que les resulta impropia, que prescribe y proscribe comportamientos, que establece sanciones y procedimientos para resolver conflictos (si es que los resuelve) de manera a priorística y descontextualizada de la realidad psicológica, social, económica y cultural de los jóvenes. En esta medida, la escuela es vivida por los jóvenes como un espacio inalterable sobre el cual no tienen ninguna injerencia y que ofrece sólo dos alternativas: adaptarse o no adaptarse.

La escuela, en esta representación social, entrega conocimientos y establece metodologías que resultan poco significativas, aburridas y desmotivantes. La escuela se vivencia como un espacio poco gratificante en lo afectivo, inútil para lograr un mejor presente y futuro laboral, y coartador de la expresión e iniciativa juvenil.

En síntesis, la representación social de la escuela en este grupo de jóvenes se funda en un sentimiento de malestar que, en lugar de movilizar acciones y reflexiones, conduce a reafirmar la condición de desescolarizado; pues, ni por angas ni por mangas visualizan la posibilidad de obtener mejorías en su condición de vida mediante la reescolarización. 


\section{SÍNTESIS Y DISCUSIÓN}

\section{La escuela como institución total: la escuela o el vacío}

Si bien la escuela no cumple con todas las características que definen a las instituciones totales, ${ }^{3}$ su carácter absorbente es incuestionable; la mayor parte del tiempo infantil y juvenil se remite a la escuela, se circunscribe al territorio concreto delimitado por las rejas del establecimiento y a la distribución de las actividades intencionadamente estructuradas por las autoridades educadoras. Por otra parte, la más grande responsabilidad que les compete a los jóvenes-alumnos, si no la única, es desempeñarse en el rol de estudiantes.

Por lo demás, cuando no se está en la escuela, los niños y jóvenes se encuentran a la sombra de ésta. Queremos decir que la gran parte, o al menos la más importante del tiempo no escolarizado de los jóvenes-alumnos (entiéndase fuera de las paredes del establecimiento educacional), está paradójicamente disponible para la realización de los deberes escolares; lo que trae consigo la escolarización general de la vida de los sujetos, mediante la prolongación psicológica y social de los muros de la institución.

No es del todo casual que la gran mayoría de los jóvenes entrevistados, a pesar de tener un grado de escolarización mínimo que no supera el cuarto o quinto año básico, tienen un grado de institucionalización mucho mayor; es decir, aunque no alcancen un alto nivel educativo, los años que pasan en la institución escolar son los suficientes, pues la mayoría de estos jóvenes tienen historias escolares prolongadas, de no menos de ocho años. Cabe preguntarse entonces acerca de qué es lo verdaderamente relevante: el curso al que llega el alumno o los años que pasa dentro de la escuela.

3 Las instituciones totales son caracterizadas por Erwin Gofmann como aquellas en que: «primero, todos los aspectos de la vida se desarrollan en el mismo lugar y bajo la misma autoridad única. Segundo, cada etapa de la actividad diaria del miembro se lleva a cabo en la compañía inmediata de un gran número de otros, a quienes se da el mismo trato y de quienes se requiere que hagan juntos las mismas cosas. Tercero, todas las etapas de las actividades diarias están estrictamente programadas, de modo que una actividad conduce en un momento prefijado a la siguiente, y toda la secuencia de actividades se impone desde arriba mediante un sistema de normas formales explícitas, y un cuerpo de funcionarios. Finalmente, las diversas actividades obligatorias se integran en un solo plan racional, deliberadamente concebido para el logro de los objetivos propios de la institución» (Gofmann, 1992:19-20). 
Decimos que el grado de institucionalización es suficiente porque, si bien los jóvenes en su discurso revelan carecer de un significativo número de conocimientos contemplados en sus programas de estudio, reduciéndose éstos a leer y escribir de manera precaria y sumar y restar con dificultad; revelan también, en el mismo discurso, algún conocimiento en torno a las materias extracurriculares que se aprenden en la escuela, vale decir, el currículum oculto del que hablan algunos autores (Bernstein, Magendzo, Stenhouse, entre otros), o las relaciones sociales al interior de la escuela de las que hablan otros (Fernández Enguita, 1990). Estas relaciones son percibidas y experienciadas por los jóvenes, y salen a la luz al momento de hablar de la disciplina escolar y de lo importante que es ésta, como contenido de enseñanza y como medio de la misma.

Los jóvenes, en muchos casos, valorizan la escuela en función de que aprenden determinadas pautas conductuales; aprenden, en sus propias palabras, a no ser «tan rebeldes». Dicho de otro modo, el curso o grado que alcanzan la mayoría de los jóvenes entrevistados no basta para dominar el interesantísimo cúmulo de conocimientos que entrega la escuela (entiéndase la ironía) a modo de materia de enseñanza explícita; pero sí es suficiente para que los jóvenes aprendan aquello que no forma parte de los programas de las diferentes asignaturas, pero que unifica y da coherencia al aprendizaje escolar: la disciplina, la obediencia y el respeto a la autoridad.

$\mathrm{Al}$ ir un poco más allá con esta reflexión, encontramos que además de ser una institución totalmente absorbente del tiempo real y psicológico de los jóvenes-alumnos, se trata de una institución absoluta. Queremos decir con esto que la escuela no deja espacio posible para el desarrollo de caminos alternativos de formación académica, de desarrollo psicológico y social de nuestros jóvenes; agudizándose esto en los sectores más desfavorecidos de la sociedad, que son justamente los sectores a los que se les ha enseñado a confiar y se les ha instado a depositar sus esperanzas de movilidad social en la educación y, en consecuencia, en la escolarización de la prole.

En esta medida: ¿qué hay más allá de la escuela en la vivencia del «pobre desescolarizado»? Nada. Postulamos que más allá de los muros de la escuela se encuentra el vacío y la deslegitimación social. La escuela y la escolarización se constituyen en el pilar fundamental para ser, en las palabras de los mismos jóvenes entrevistados, «alguien en la vida», «sin cuarto medio no valís nada». El derecho a la educación, tan bien pensado y tan bien intencionado por y para los que go- 
biernan, se convierte para los jóvenes más pobres de nuestro país, en especial de zonas urbanas, en una verdadera pesadilla en la que se les invita a transitar por un camino difícil e impropio. En resumidas cuentas, se les presentan la educación y la escuela como un derecho y una invitación, no obstante constituyan una obligación y una imposición.

\section{La disciplina escolar: ¿̇orientación o vigilancia?}

La disciplina es concebida en el marco escolar al menos con una doble acepción; por una parte es un componente fundamental para que los procesos de enseñanza-aprendizaje se lleven a cabo y por otra es en sí misma un contenido a ser transmitido en esta relación.

Los requerimientos de orden, silencio, puntualidad, respeto a la autoridad y obediencia en general, predominan en el discurso de los jóvenes entrevistados, relegando a un segundo plano a los otros componentes de la relación enseñanza-aprendizaje, como son los contenidos y las metodologías. Siguiendo esta idea, el rol disciplinario de la escuela emerge en el discurso de los jóvenes como el componente que funda la institución; la escuela aparece como el lugar en que se norman, normalizan y supervisan las conductas individuales y las relaciones sociales que establecen los niños y jóvenes, pauteando con esto, las conductas y las relaciones sociales futuras.

Ahora bien, ¿cuáles son los comportamientos y las relaciones sociales que promueve la escuela? Los jóvenes describen como pautas conductuales aceptadas aquellas que dicen relación con la formalidad (presentación personal), la puntualidad, la obediencia a los profesores e inspectores, la quietud y el silencio en las clases, los hábitos de estudio, cumplimiento de las exigencias académicas; todas las que se subordinan a relaciones sociales marcadas por la verticalidad.

Las posiciones en la jerarquía escolar están claramente explicitadas y encarnadas y, en función de esto, se exige a los jóvenes estudiantes la obediencia y el respeto a los adultos que detentan estos puestos de poder, los que a su vez son los encargados de desempeñar el rol vigilante para unos y orientador para otros.

El rol disciplinario de la escuela es vivenciado por los jóvenes en función de esta tensión: por un lado lo necesario y positivo que puede resultar educarse por y en esta disciplina, y por otro lado, lo coercitivo y castrador que puede resultar educarse de esta manera, dentro de un marco rígido y restringido. Es justamente esta tensión la que funda la construcción de las dos representaciones sociales de la 
escuela en los jóvenes entrevistados.

La disyuntiva antes planteada atraviesa la experiencia escolar de los jóvenes y condiciona su posición en el escalafón jerárquico, los pone en una situación sin salida, de la que no hay escape; por una parte, la demanda por orientación que vaya más allá de la familia es clara, evidente y necesaria; y por otra parte, la vigilancia y el castigo son absolutamente indeseados y desagradables. La escuela es el único espacio que ofrece esta orientación extrafamiliar, pero lo hace en las condiciones antes mencionadas.

Dos son las posibilidades: la desescolarización o el sometimiento incondicional a la normativa escolar. La primera trae de la mano una sanción social considerable; el individuo se convierte en un indisciplinado, un vago; en resumidas cuentas, en un desorientado, en un mal educado, que además se siente responsable y culpable de su fracaso. La segunda trae consigo la identidad estudiantil y el reconocimiento social que ésta implica al precio de soportar largos años de institucionalización, alimentando la ingenua esperanza de un futuro mejor.

En consecuencia, las dos posibilidades resultan castradoras; pues por una parte, se deslegitima cualquier aprendizaje o tipo de educación que se realice fuera de los tiempos y espacios de la institución, y por otra parte, el quedarse adentro implica la restricción de muchas dimensiones del desarrollo juvenil individual y colectivo si no se condicen con las condiciones establecidas por la escuela. Quedan en las puertas de la escuela el lenguaje y los códigos ${ }^{4}$ conversacionales propios de los jóvenes, dinámicas juveniles como las peleas, los juegos, la libre plática, los amigos del barrio, la ropa, el corte de pelo y todo lo relacionado con el mundo juvenil y poblacional.

En la escuela los jóvenes confunden sus formas de pasarlo bien con desorden, pues los códigos de la institución los equiparan, particularmente en la sala de clases. En esta medida, los jóvenes se ven en la obligación de permutar sus propios códigos por los de la escuela, terminando esto en una aceptación incondicional e irreflexiva

4 Bernstein comprende el concepto de código como un dispositivo de posicionamiento culturalmente determinado y que posiciona en términos de las relaciones de poder que se establecen en la escuela, éste funciona como un principio regulador, adquirido de forma tácita y que selecciona e integra: significados relevantes, formas de realización de los mismos y contextos evocadores; la escuela entonces se convertiría en el canal por medio del cual los niños son socializados en estos códigos. 
de la norma; aceptación que muchas veces se justifica en la esperanza del mejoramiento de las condiciones de vida a futuro; pero que otras tantas, encuentra su asidero en el poder intrínseco de la disciplina escolar y la posición estructural de la escuela en el sistema social.

El rol disciplinario de la escuela se orienta principalmente a evitar la conducta proscrita más que a promover los mismos comportamientos que prescribe. La escuela aparece entonces como una institución preventiva y represiva, en lugar de constituirse en un espacio promotor del desarrollo individual y colectivo de los jóvenes, en términos de facilitar y legitimar las expresiones de la diversidad.

Finalmente, la disciplina, el orden y la obediencia, se erigen en el discurso de los jóvenes como los contenidos y metodologías de enseñanza significativos. La disciplina como herramienta, como contenido y como fin de la educación escolarizada.

\section{La alienación en la experiencia escolar}

Una cosa es clara: las escuelas se llenan de alumnos, y son éstos los que en definitiva dan vida y sentido al espacio escolar. No obstante, la participación que estos tienen en la escuela y las posibilidades de apropiarse de su propia experiencia escolar y de ser protagonistas de su proceso educativo son prácticamente nulas. Los niños y jóvenes llegan a ocupar un territorio totalmente predeterminado.

En el discurso de los jóvenes entrevistados lo anterior se manifiesta como una sensación de extrañeza, en lo ajeno que les resultan los componentes fundamentales de la dimensión académica de su experiencia escolar: los contenidos, las metodologías, el proceso de aprendizaje y los fines de la educación. Para nombrar este fenómeno, utilizaremos el concepto de alienación tal como lo entendiera y aplicara Marx al fenómeno del trabajo en la sociedad capitalista. ${ }^{5}$

En este sentido, la relación que establecen los jóvenes entrevistados con los contenidos de enseñanza es una relación alienada. La selección de los saberes a ser enseñados en el seno de la escuela es previa a la llegada de los alumnos, y poco y nada tiene que ver con el contexto vital particular de los jóvenes urbano populares. Los cono-

5 «Marx caracterizó certeramente el trabajo en la sociedad capitalista, frente al trabajo en general, como trabajo alienado. Para él, esta alienación residía, básicamente, en la relación entre el trabajador y el producto, el proceso y los medios de su trabajo» (Marx, citado en Fernández Enguita, 1990:188). 
cimientos, las experiencias, los deseos, las capacidades, etc., que los jóvenes puedan traer a la escuela, pierden su importancia en favor de lo que la institución escolar predetermina como correcto y necesario.

En el discurso de los jóvenes, los contenidos de enseñanza escolar se caracterizan como poco significativos y descontextualizados; y en su máxima expresión se reducen a conocimientos mínimos y restringidos, que resultan así mismo de una utilidad mínima y restringida, como tomar la micro y dar vuelto (castellano y matemáticas). Del mismo modo, la alienación se manifiesta por la escasa mención, o bien, la omisión de referencias respecto al tema. La poca significatividad de los contenidos de enseñanza es reflejada en el espacio real que el tema ocupa dentro del discurso, además de la constante oposición y comparación que los jóvenes suelen hacer entre los contenidos del aprendizaje escolar y los contenidos del aprendizaje callejero.

De acuerdo a lo anterior, los jóvenes se encuentran entrampados en la dinámica de la validez social de los contenidos de aprendizaje escolares, versus la utilidad y necesidad cotidiana de contenidos de aprendizaje extraescolares. La arbitraria selección de los contenidos a ser enseñados por la escuela implica también una deslegitimación de cualquier otro contenido; más aún si éstos tienen lugar fuera del territorio escolar, lo cual se hace más evidente y dramático cuando se trata de sectores de la población que viven en condiciones de marginalidad y pobreza. Para estos jóvenes la escuela se constituye, en el mejor de los casos, en un sinsentido necesario.

En términos metodológicos, en el discurso de los jóvenes pueden apreciarse ciertos matices, que van desde la incomodidad y desagrado con ciertas técnicas o formas de entrega de conocimientos hasta lo atractivo que otras les puedan resultar. No obstante, éstas siempre dependen de la voluntad ajena, en este caso específico, del profesor. Esta salvedad es posible en el ámbito metodológico, mas no en el de los contenidos o fines de la educación; pues éstos trascienden incluso la voluntad de los docentes y hasta de las mismas escuelas.

De todas maneras nos resulta relevante que para los jóvenes las metodologías atractivas se caractericen por la mayor actividad y protagonismo que les otorga y por la posibilidad del trabajo grupal o colectivo, centrado en lo cooperativo; en oposición a las metodologías que les otorgan un rol pasivo y de escucha y se centran en lo individual y competitivo. Del mismo modo, es menester destacar que las metodologías que los jóvenes consideran atractivas tienen un carácter excepcional y recreativo en relación a la predominancia de las meto- 
dologías tradicionales.

Además de no poder determinar ni tener participación alguna en la definición de los contenidos y las metodologías de enseñanza, los jóvenes entrevistados evidencian en su discurso la imposibilidad de tomar parte en las decisiones respecto a su proceso de aprendizaje y a la situación de aprendizaje escolar. Es así como manifiestan el no darse cuenta del cómo adquieren los aprendizajes, lo que redunda en el rápido olvido de los mismos; pues es el aprendizaje memorístico el que prima en el proceso. Llevando esta paradoja a su extremo podemos decir que el proceso de aprendizaje no es tal, pues se reduce a un registro de datos muchas veces inconexos, dejando todo en manos de la memoria, la cual, como todos sabemos, es frágil (particularmente en nuestro país). ${ }^{6}$

Los jóvenes han de aceptar pasivamente las decisiones en torno a los tiempos y los espacios escolares, son sometidos a un horario, a una sala de clases y a una distribución inteligentemente arbitraria de las materias. Los estudiantes están conscientes de la duración de las horas de clases, de la distribución diaria de los ramos en estas horas, de la disposición espacial de la sala de clases (sillas y pupitres rígidamente ordenadas cuyo norte es la tarima, pizarra y mesa del profesor), saben que pueden hablar sólo cuando el profesor lo solicite o lo permita, etc.; todo lo cual es asumido como normas básicas e inmodificables para hacer posible el proceso de enseñanza en la escuela, y ante lo cual no se vislumbra la más remota posibilidad de participar en un cambio, por mínimo que sea, a menos que el profesor o la institución se lo permitan.

No conforme con lo anterior, la escuela ha sido pensada y edificada para la consecución de ciertos fines que también son definidos por la institución en el marco de intereses sociales, culturales, económicos y políticos propios de los grupos dominantes; y en esta medida, impropios de los grupos dominados, entre los cuales, por cierto, se encuentran los jóvenes y particularmente, los jóvenes pobres. «La escuela es por tanto, la institución investida de la función social de enseñar y por esto define lo que es legítimo aprender. Esta acción pedagógica impone como legítima la cultura de la clase dominante, en este proceso enmascara su naturaleza social presentándola como la cultura objetiva indiscutible, rechazando al mismo tiempo las culturas de los otros grupos sociales, la acción pedagógica sería la acción que

6 Revisar la noción de la compulsión al olvido en Moulian, 1997. 
impone significación y las impone como legítimas» (Herrera, 1999:183).

Sin embargo, un grupo de los jóvenes entrevistados, por razones fundamentalmente de aceptación y validación social, comparte los fines explicitados por la escuela, que como ya lo hemos señalado, refieren principalmente a mejorar las condiciones de vida y a formar ciudadanos bien educados útiles a la sociedad, en tanto trabajadores honrados, responsables y obedientes. Mas el que estos fines sean aceptados, no implica que sean propios, manteniendo su carácter alienado.

Para otro grupo de jóvenes tales fines son lisa y llanamente vividos como impuestos e inalcanzables, pues su realidad indica que la escuela no es el camino que les garantiza cualquier mejora a las condiciones de vida; por el contrario, muchas veces la asistencia a la escuela significa perder tiempo real para efectuar alguna actividad que les reporte satisfacciones afectivas y efectivas, sociales o económicas.

En definitiva, la escuela, en las representaciones sociales del grupo de jóvenes entrevistados, emerge como una institución que les resulta ajena y con la cual se establece una relación alienada respecto a los ejes que la justifican socialmente en su expresión actual: lo disciplinario y lo académico.

La escuela y lo que en ella se enseña se constituye en un sinsentido necesario, pues en sí misma no es significativa, pero socialmente es lo que le brinda validez y legitimidad al período juvenil en general. En la escuela cualquier cosa que se aprenda, por irrelevante que resulte, es legítima y por tanto es tiempo bien aprovechado. Son la escuela y la escolarización los que fundamentan y validan el legítimo aprendizaje: el aprendizaje escolar, impuesto y descontextualizado, por decir lo menos. «La acción pedagógica da como resultado la reproducción de las relaciones de clase [...]. Cada acción pedagógica tiene, pues, una eficacia diferenciada en función de las diferentes caracterizaciones culturales preexistentes de los sujetos y que son de naturaleza social. La escuela, al sancionar estas diferencias como si fueran puramente escolares, contribuye al mismo tiempo, a reproducir la estratificación social y a legitimarla asegurando su exteriorización y persuadiendo a los individuos que ésta no es social sino natural» (Bourdieu, Passeron, 1996:17).

La escuela invita a los niños y jóvenes a competir individualmente por la posibilidad de un ascenso social; por que cual se asume también que el tema de la superación de la pobreza en Chile pasa por responsabilidades individuales, y no por esfuerzos colectivos; pasa 
exclusivamente por la mejoría de las condiciones materiales inmediatas e individuales, evitando cualquier transformación de la estructura social.

Sostenemos que la consolidación del modelo de sociedad y el proyecto de país, que defienden y promueven, con mínimos matices, tanto el gobierno de la concertación como la derecha parlamentaria, tiene en la escuela un pilar fundamental; pues gracias a su excelente labor, se contribuye a evitar o limitar cualquier posible perturbación al sistema desde cualquier sector, pero sobre todo desde los grupos o individuos más desfavorecidos socioeconómicamente, los cuales han de esperar y confiar en que los planes y los tiempos de los gobernantes les permitan mejorar sus condiciones de vida, cuando puedan acceder a más y mejores bienes de consumo, mejorando así su calidad de vida y siendo un poco más felices o más bien un poco menos tristes.

\section{REFLEXIONES Y PROPUESTAS FINALES}

La escuela de las representaciones sociales de los jóvenes urbano populares desescolarizados, que de alguna manera se refleja a lo largo de este estudio, no es fruto de la pura y nefasta imaginación del sujeto social que se la representa ni de los investigadores que la explicitan; pues deviene de un objeto social real, de un modelo educativo real que cobra sentido en función de una idea de sociedad y de un proyecto de país específico.

No está demás explicitar que las propuestas que se plantean a continuación se circunscriben en una idea de sociedad distinta. Donde se pretende legitimar espacios educativos desescolarizados y orientar a la escuela hacia la formación integral y ciudadana de los niños y jóvenes de nuestra sociedad. Las propuestas que se presentan a continuación se plantean como posibles respuestas a los nudos críticos desarrollados en el punto anterior.

i) De la institución total al desdoblamiento del espacio educativo. Consideramos una tarea prioritaria el revertir el carácter exclusivo y excluyente de la institución escolar e impulsar procesos de legitimación de los espacios sociales desescolarizados.

Lo anterior supone redestinar los recursos que hoy se emplean en sobreescolarizar a los jóvenes y niños — habilitando las escuelas para una jornada escolar completa - para implementar programas educativos en los contextos sociales más inmediatos de estos jóvenes. 
Esto implica relevar las múltiples posibilidades de establecer relaciones de enseñanza-aprendizaje desescolarizadas, y junto con ello, valorar el protagonismo y la apropiación de contenidos y metodologías, contextualizados a la cotidianeidad y diversidad de la cultura juvenil urbano popular.

Se trata de facilitar procesos donde los jóvenes se piensen a sí mismos, como individuos y como colectivo, y puedan desarrollar habilidades cognitivas y sociales que les permitan actuar sobre su propia vida y su entorno. Es decir, ser protagonistas de su propio desarrollo psicosocial.

ii) De la disciplina escolar a la construcción participativa de los límites. Es menester hacer la distinción entre los límites que supone la imposición de una normativa disciplinaria, que preexiste a los alumnos, y la necesaria y demandada explicitación de límites que signifiquen una orientación o contención para los jóvenes.

En la medida que se construyen objetivos compartidos, se pueden establecer acuerdos de convivencia que orienten lo que es más apropiado de realizar para el logro de dichos objetivos. De este modo la norma disciplinaria se diluye dando lugar a un rayado de cancha compartido y conocido, que recoge la demanda de límites de los jóvenes, generando un nuevo código fruto del diálogo entre los jóvenes y los educadores.

iii) De la alienación a la apropiación ciudadana de la experiencia educacional. Es posible y necesario involucrar a los jóvenes en la construcción de sus propios centros educacionales. La apropiación del espacio educativo escolar implica la participación de los jóvenes en su totalidad, con sus códigos, dinámicas, juegos, amigos, ropas y todo lo relacionado con el mundo juvenil y poblacional. Sólo de este modo se puede establecer un diálogo real que permita enriquecer el diseño de planes y programas de estudios, metodologías y el proyecto educativo del centro, estableciendo las condiciones necesarias para que los jóvenes participen en la toma de decisiones en su escuela. Siendo esto una verdadera y efectiva preparación para una vida ciudadana activa donde los jóvenes se involucren tempranamente en la construcción de la sociedad, en la que no sólo les toca vivir, sino de la que son responsables.

La escuela de las representaciones sociales de los jóvenes urbano populares se funda en sancionar las diferencias entre las juventu- 
des, proponiendo una supuesta escuela para todos. Nuestra propuesta supone el reconocimiento y validación de las diferencias para trasformarlas en una diversidad, a partir de la cual se construyan espacios educativos contextualizados y que se orienten a la formación de actores sociales que hagan pleno ejercicio de su ciudadanía, participando en la construcción de la sociedad desde una perspectiva crítica.

SANTIAGO, SEPTIEMBRE DEL 2001

\section{BIBLIOGRAFÍA}

BOURDIEU, P. y PASSERON (1996): La reproducción: elementos para una teoría del sistema de enseñanza. México: Fontamara.

DÁvILA, O. (1998): «Exclusión social y juventud popular». Última Década ${ }^{\circ} 8$. Viña del Mar: Ediciones CIDPA.

FARR, R. (1986): «Las representaciones sociales». En S. MoscovicI (editor): Psicología social II. Pensamiento y vida social, psicología social y problemas sociales. Barcelona: Paidós.

FERNÁNDEZ ENGUITA, M. (1990): La cara oculta de la escuela. Madrid: Siglo XXI Editores.

GofFMAN, E. (1990): Internados. Buenos Aires: Amorrortu.

HERRERA, M. (1999): «Fracaso escolar, códigos y disciplina: una aproximación etnográfica». Última Década N¹0. Viña del Mar: Ediciones CIDPA.

JODELET, D. (1986): «La representación social: fenómenos, concepto y teoría». En S. Moscovici (editor): Psicología social II. Pensamiento y vida social, psicología social y problemas sociales. Barcelona: Paidós.

Moulian, T. (1997): Chile actual. Anatomía de un mito. Santiago: LOM-ARCIS.

REDONDO, J. (1997): «La dinámica escolar: de la diferencia a la desigualdad». Revista de Psicología Nº6. Santiago: Universidad de Chile.

(1994): «Análisis de la situación social de los jóvenes desfavorecidos y propuesta de un programa integral de garantías sociales». Tesis Doctoral, Universidad de Deusto, Bilbao.

SALAZAR, G. (1996): «Las avenidas del espacio público y el avance de la educación ciudadana». Última Década $\mathrm{N}^{\circ} 4$. Viña del 
Mar: Ediciones CIDPA.

SOTO, V. (1996): «Teorías críticas y currículo». Santiago: UMCE.

WEINSTEIN, J. (1990): «Juventud urbano popular: la otra juventud». En E. RODRÍGUEZ y B. DABEZIES: Primer informe sobre la juventud de América Latina. Quito: Conferencia Iberoamericana de Juventud. 